\title{
Zibo Fish Plates: From Folk Art to Cultural Heritage
}

\author{
Ke Sun \\ Culture and Leisure Research Institution \\ Shandong University \\ Weihai, China 264200
}

\begin{abstract}
Zibo fish plate, also called as "Shandong fish plate", is a porcelain plate-shaped ware with fish-pattern paintings for daily use to meet people's daily needs, which was mainly produced in places like Boshan and Bochuan in Zibo City, Shandong Province in the history, and which was popular in regions of Shandong. Zibo fish plate is derived from the folk, with a long history. The fish plate, reaching its period of great prosperity in the late Qing Dynasty, is the excellent representative of Zibo folk porcelain art and the important carrier of the inheritance of Zibo traditional porcelain techniques. Zibo fish plate, as the comprehensive carrier of matter, technique, art and culture, is not only a precious folk art, but also an important folk cultural heritage.
\end{abstract}

Keywords-Zibo fish plates; folk art; traditional techniques; cultural heritage

\section{INTRODUCTION}

Zibo fish plate, also called as "Shandong fish plate", is a porcelain plate-shaped ware with fish-pattern paintings for daily use, fired by kilns in Zibo area (mainly distributing in places like Boshan and Zichuan, etc.). Zibo fish plate, called "the representative of Zibo soil-texture blue-and-white porcelain", is the excellent representative of Zibo folk porcelain art and the important carrier of the inheritance of Zibo traditional porcelain techniques. Zibo fish plates are all produced by traditional handicrafts, with hand-drawn fish patterns on the plates and smooth lines, vivid, concise and beautiful.

Zibo of Shandong, with rich natural resources and profound culture, is one of the famous cultural and historical cities in China. Zibo, as one of the main folk porcelain producing places, has a long history of porcelain production; the earliest porcelains of Zibo were produced 8000 years ago. The unique porcelain making techniques of Zibo kilns have held up a massive history, techniques, and cultural artistic value. The eggshell porcelains produced in Longshan Culture Period (4300-4600 years ago from now) and the lotus porcelains with blue glaze produced in the Northern and Southern Dynasties (A.D. 420-581) are the condensation of Zibo people's intelligence and wisdom. According to textual research, Zibo porcelain production started from the late Northern Dynasty and Tang Dynasty, with a 1400-year history before now. Zibo is one of the earlier places where porcelains were fired.

Zibo fish plate, as the representing implement of Zibo porcelain techniques, is the typical representative of Chinese Northern folk kiln porcelains. Zibo fish plates are simple and natural, whose patterns reveal the simplicity of Shandong people's items. Those plates are made by different craftsmen and show different changes and creative ideas based on the maintaining of basic fish pattern forms, and they are very popular daily folk wares widely used in places of Shandong, especially in the middle of Shandong and peninsula areas.

As for the origin and development of Zibo fish plate, there is no existing ancient document and book with clear and definite records, and the porcelain art circle also has different opinions on them. Some scholars pointed out that the production of Zibo fish plate could be traced back to the Warring States period around 2200 years ago, for at that time plate-shaped wares with fish patterns had started to be used in Zibo region. Some scholars, according to the textual research of unearthed objects, thought that the production of Zibo fish plate was supposed to be traced back to the Northern Song Dynasty. Some pots with white glaze, black decorations and fish patterns were excavated out of Zichuan Western Slop kilns in Yuan Dynasty; some plates with blue-glaze stamping and fish patterns were unearthed out of Boshan Avenue kilns in Jin and Yuan Dynasties. Moreover, some scholars admitted that the production of Zibo fish plate started from the middle and late Qing Dynasty, and reached its great prosperity period in the late Ming Dynasty and the republic of China, and gradually declined after the establishment of new China.

The reas on why there are different opinions on the origin of Zibo fish plate is that there are different views on the definition standard of Zibo fish plate. For the definition standard, I think it can be mastered according to the following basic elements: first is, on the aspect of space, whether the plates were historically produced in Zibo and regions around Zibo; second is, on the aspect of textures, crafts and techniques, whether Zibo traditional porcelain crafts were applied and whether porcelain was used as carrier; third is, on the aspect of decoration, whether the plates were painted by patterns, main ly fish patterns (other decoration patterns can be used as well).

Based on all mentioned above, every plate-shaped porcelain ware with fish pattern painting, which was fired by traditional porcelain craftsmanship and historically produced in Zibo and surrounding places, can be classified into the category of Zibo fish plate. Therefore, on the basis of existing unearthed and handed down implements, it can be decided that the origin of Zibo fish plate can be traced back to 2200 years ago, the Warring States Period; and it reached its great prosperity period in the late Qing Dynasty and the Republic of China. 


\section{THE HistoricAl DEVELOPMENT, CATEGORIES AND ART IST IC CHARACTERISTICS OF ZIBO FISH PLATE}

According to the fish plate objects handed down and unearthed as well as relevant literature materials, the author sorted out the developmental historical period, categories and artistic characteristics of Zibo fish plate, and divided the period into five periods, including culture origin period, newly establishment period, development period, prosperity period and continuation period:

\section{A. The Culture Origin Period(Before the Ming Dynasty)}

Before Ming Dynasty, plate-shaped wares with fish patterns were produced in Zibo region, but they were of a small number and didn't form a scale. According to local archaeological activities, it was found that as early as 2200 years ago in the Warring States period, ancient people of Zibo had started using fish patterns to decorate porcelain plate-shaped wares, and the porcelain bodies of those wares at that time were red brown, with simple and unadorned fish patterns painted by white pigment, accompanied by rolling cloud patterns and triangle patterns, etc. at the same time "Fig. 1".

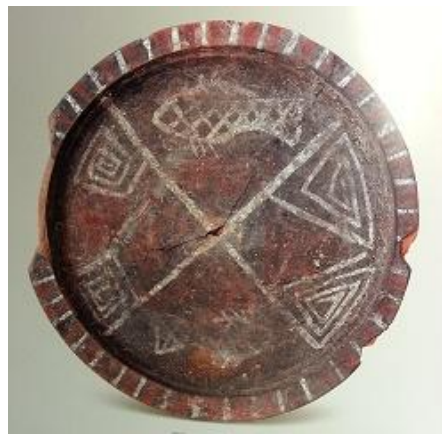

Fig. 1. A color-painting porcelain fish plate produced during the Warring States Period

The period of Song Dynasty and Jin Dynasty is the emerg ing period of Zibo ancient porcelain development, and during that period exquisite fish-pattern plates were produced in Zibo kilns. At that time, sand loop superposition firing method was chosen as the firing technique of fish plates, with neat modeling and exquisite production; the carving, stamping, cutting off and sauce-color fish patterns of the plates are of unique features and clever image composition "Fig. 2", "Fig. 3".

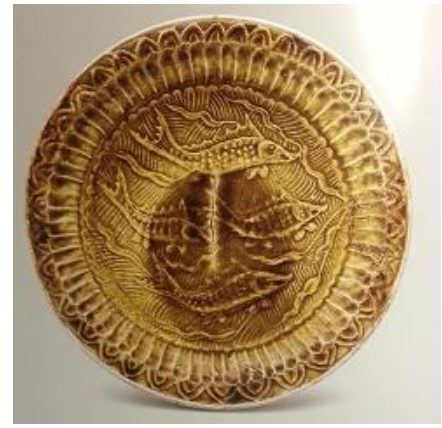

Fig. 2. A blue-glaze fish plate produced in Song Dynasty.

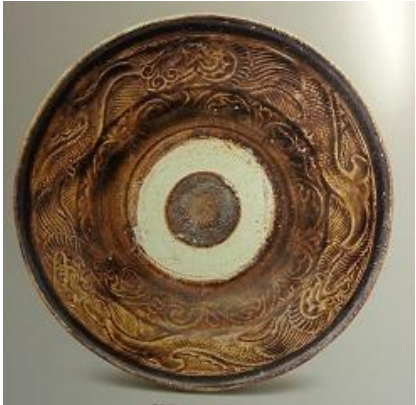

Fig. 3. A blue-glaze fish plate produced in Jin Dynasty

In addition, the white-glaze fish plates with black-painting fish patterns unearthed from the slope kilns in Yuan Dynasty are of big shape; the fish decorations, rough and unrestrained, are the early sound of the colorful decoration under glaze of Zibo fish plate. The Zibo fish plate in the early Ming Dynasty continued the stylish characteristics of Yuan Dynasty, mainly dominated by white-glaze and black-painting plates; the fish patterns are simple but not lacking in temperament and interest, and the glaze colors are quietly elegant and rich in implications "Fig. 4".

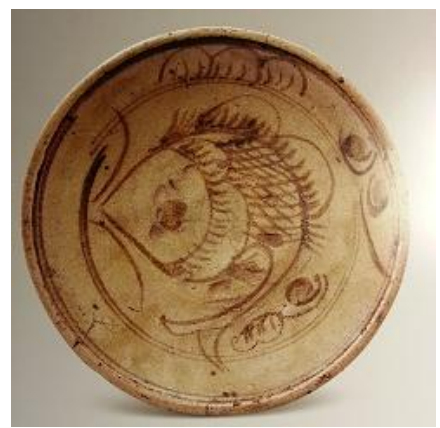

Fig. 4. A white-glaze fish plate produced in Ming Dynasty with a blackpainting fish pattern.

\section{B. The Newly Established Period (From the End of Ming} Dynasty to the Beginning of Qing Dynasty)

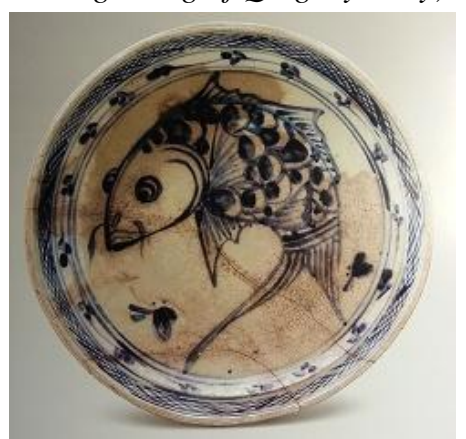

Fig. 5. A blue-and-white porcelain fish plate produced in the late Ming Dynasty

In the late Ming Dynasty, the Western River kiln in Zibo started using asbolite ore as the painting material of porcelain production, and started the batch firing of white-glaze, blueand-white porcelain fish plates "Fig. 5". Blue-and-white porcelain fish plates use blue-and-white porcelain painting 
materials to draw fish patterns, apply transparent glaze, and finish firing once for all under a high temperature around 1300 degree centigrade. The fish plates at that time had fish patterns with outstanding topics and full image compositions, uncovering the new chapter of the under-glazed, blue-andwhite porcelain of Zibo fish plate and setting a foundation for the forming of the prosperity and artistic style of Zibo fish plate production in the late Qing Dynasty and the Republic of China. The period of the late Ming Dynasty and the early Qing Dynasty is the newly establishment period of Zibo fish plate, during which Zibo fish plate was officially born.

\section{The Developmental Period (In the Middle of Qing Dynasty)}

Zibo fish plates in the early Qing Dynasty inherited the realist style in the late Ming Dynasty. The paintings on the plates were mainly blue-and-white with other colors and precise image compositions, right at the newly establishment stage; the color and lustre were still not very pure; pattern decorations were complicated and fish patterns pursued realism. In the middle of Qing Dynasty, the techniques of firing and painting improved; fish patterns were outlined by blue decorations; the main body was outstood and the parts of the body were decorated by yellow-glaze color or brown-glaze color, with lotus flowers, chrysanthemu m flowers, water waves and cloud patterns as edging decorations. Elegance and gorgeousness showing a little bit richness and solemnness, the painting style was neat and delicate; fish patterns, emphasizing realis $\mathrm{m}$, showed the delicate and vivid description of fish head, fish scale and fish tail, etc., which really reflected the body features of a fish "Fig. 6", "Fig. 7".

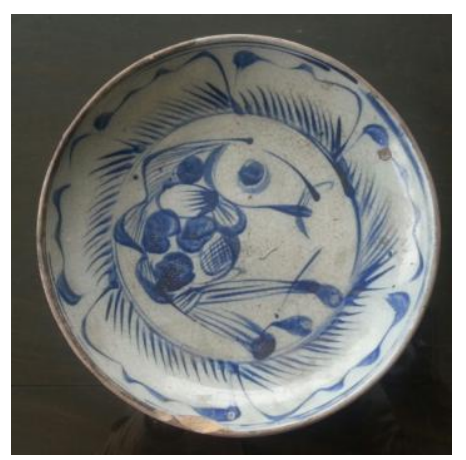

Fig. 6. A blue-and-white porcelain fish plate with a yellow color produced in the middle of Qing Dynasty

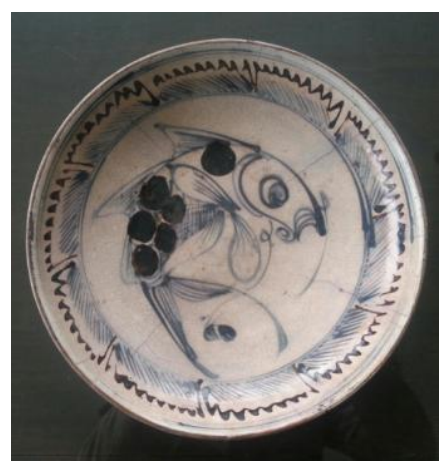

Fig. 7. A blue-and-white porcelain fish plate produced in the middle of Qing Dynasty.

\section{The Prosperity Period (From Late Qing Dynasty to the Period of the Republic of China)}

In the late Qing Dynasty, most Zibo fish plates were without edging decorations or only decorated with bow string patterns, completely taking fish patterns as expression objects; they got rid of the restraint that traditional fish plates valued realis $\mathrm{m}$, and emphasized similarity in spirit, and mainly used transformative fish patterns. At that time, the crafts of fish plate painting became matured, with countable simple and concise lines to finish the painting, lively and vividly. The plates reached a higher level of folk arts, named as the typical representative of transforming from classical porcelain art to modern porcelain art "Fig. 8".

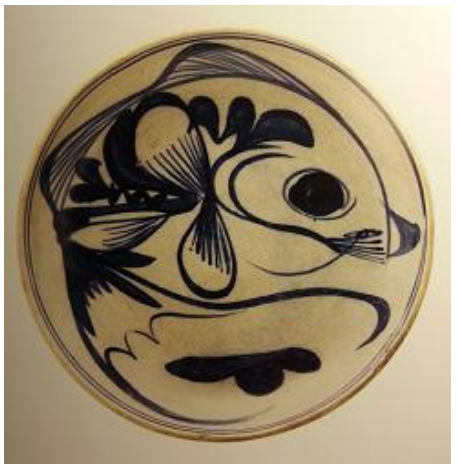

Fig. 8. A blue-and-white porcelain fish plate produced in the late Qing Dynasty

During the period of the Republic of China, the plates inherited the style in the late Qing Dynasty and had creations of new varieties, such as fish plates with red and green colors and goldfish plates, etc. During that time, the fish plates not only had skillful crafts, but also improved their production scale to a great prosperity, with exquisite crafts manship, people-friendly prices, great production and vigorous sales volume, deeply loved by the public. People in the middle of Shandong and Shandong peninsula widely used fish plates produced in Zibo as the wares in their daily life, and formed the unique cultural phenomenon of Zibo porcelain production "Fig. 9", "Fig. 10".

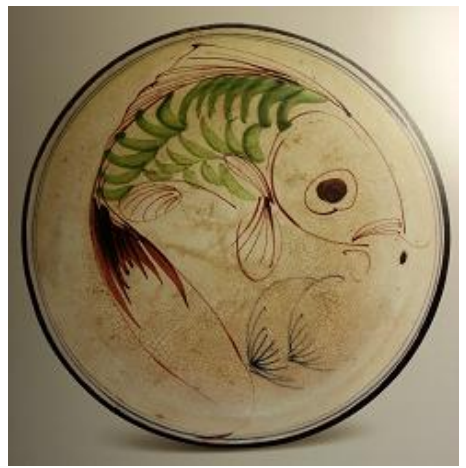

Fig. 9. A blue-and-white porcelain fish plate with red and green colors produced in the Republic of China 


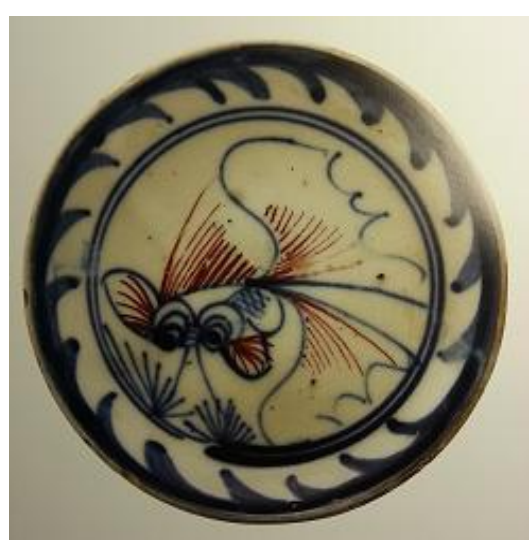

Fig. 10. A blue-and-white porcelain goldfish plate with red and green colors produced in the Republic of China.

\section{E. The Continuation Period (After the Establishment of New China)}

After the establishment of new China, with the continuous development of social production, Zibo porcelain production obtained new vitality and energy. Whether it is domestic porcelain, art porcelain or architectural porcelain, Zibo porcelain had qualities or sales volume superior to before, and Zibo became an important porcelain production region in the northern area of Yangtze River. After the establishment of new China, the inheritance and development of Zibo fish plate are mainly embodied in two aspects:

One aspect is the inheritance of the producing and painting crafts of traditional fish plates, especially the inheritance of the fish pate art during the great prosperity period in the late Qing Dynasty and the Republic of China. From 1950s to 1970s, Boshan and Fushan porcelain factories produced fish plate products in batches. At that time, the purpose of fish plate production was not merely for daily use, but also for the satisfaction of all kinds of porcelain exhibitions as well as arts and crafts exhibitions. Besides, after the establishment of new China, Chinese craft and art masters Chen Yimo, Feng Naizao and others made traditional fish-patterned fish plates before, and arts and crafts master Mr. Zhu Yigui was named as "the last person of Zibo fish plate painting" "Fig. 11", "Fig. 12".

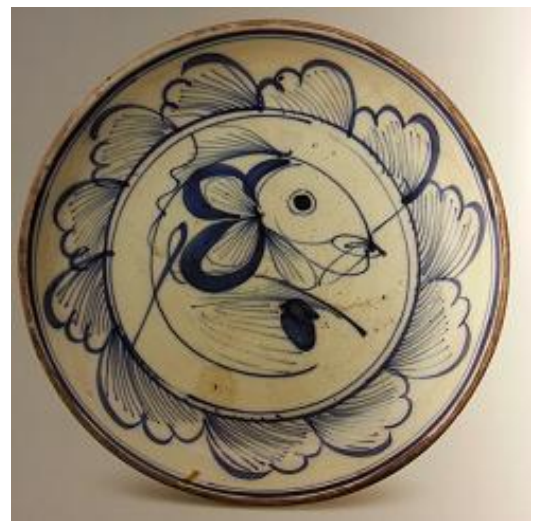

Fig. 11. A blue-and-white porcelain fish plate produced in 1950 s;

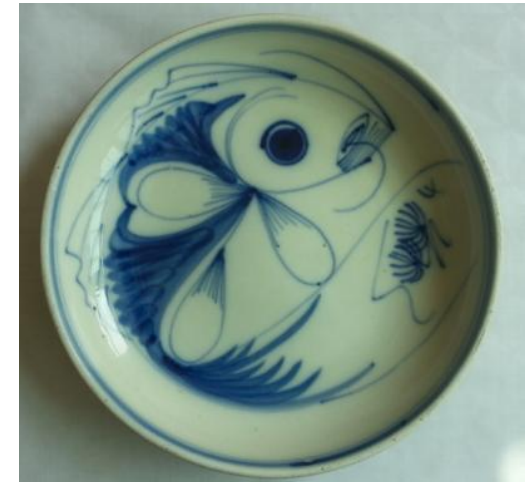

Fig. 12. A blue-and-white porcelain fish plate today.

The other aspect is that after 1980s, based on carrying forward and innovation of traditional crafts, part of Zibo porcelain art masters applied high-quality porcelain materials, and broke through the traditional forms of fish plate painting, and created works more suitable for modern aesthetics by new artistic styled fish patterns, to meet people's needs for the pursuit of beauty and household decoration "Fig. 13", "Fig. 14" "Fig. 15" and "Fig. 16".

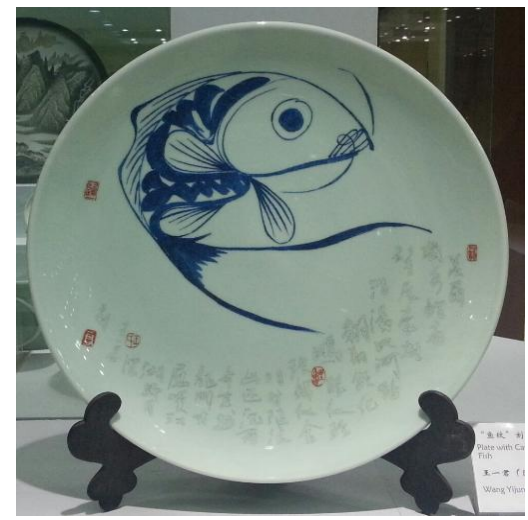

Fig. 13. A carved porcelain fish plate today

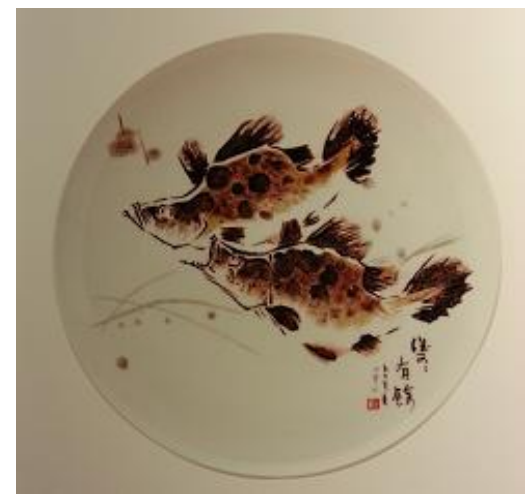

Fig. 14. A blue-glaze carved porcelain fish plate today. 


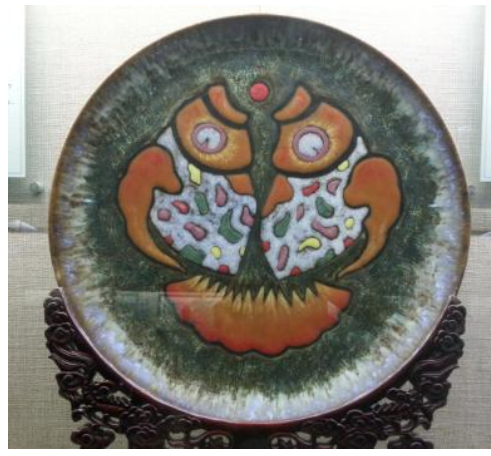

Fig. 15. A double fish plate with fancy glaze today

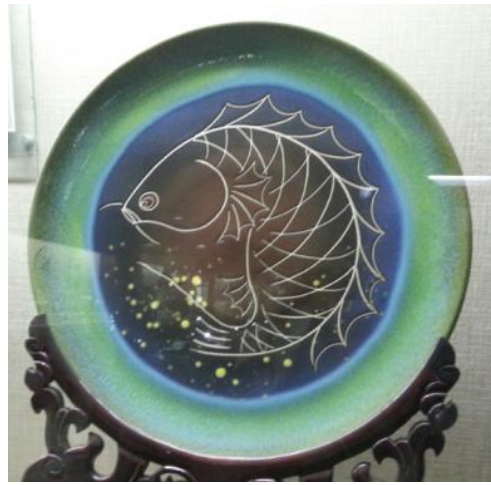

Fig. 16. A fish plate with fancy glaze today.

Throughout the long history, no matter how the developmental periods of Zibo fish plate in history are divided, the ling history of Zibo fish plate and its distinctive regional characteristics will all trigger people's beautiful thoughts and imaginations.

\section{THE CATEGORIES AND ARTISTIC CHARACTERISTICS OF ZIBO FISH PLATE}

Porcelains are the combination of soil and water and the art of refining in the fire. Zibo fish plates take the local porcelain clay as material, with a full but not disordered composition, balanced and dynamic. The lines of fish patterns are lucid and lively, fluent and smooth, concise and exaggerated as well as free and bold, showing the rich art imagination and expression of Zibo people and indicating the pure, simple, open and broad personalities and aes thetic purport of Shandong people.

According to traditional fish plates' shape and structure as well as their fish pattern painting, we can classify fish plates into different categories. For the size, they can be divided into big fish plates and small fish plates; for the number of fishes painted, they can be divided into single fish plates and double fish plates; for the breeds of fishes painted, they can be divided into carp fish plates, goldfish plates, fish plates with fish transforming into dragon and fish plates with transformative fishes, etc.; for the different painting pigments, they can be divided into blue-and-white and red-and-green, etc. The author tried to classify the plates by the differences of their fish patterns and show the characteristics of Zibo fish plate art:

\section{A. Big Fish Plates and Small Fish Plates}

According to the size difference, Zibo fish plates can be divided into big fish plates and small fish plates, which is a very apparent classification. Zibo fish plates in local areas are usually called "Zibo big fish plates", because no matter what historical period it is, the diameter of most fish plates is around 28 centimeters, and the fishes on the plates are big, and most of the fishes are carp fishes or transformative carp fishes. Among the great number of fish plates, small fish plates do not have any advantage, but the number of small fish plates is also pretty big; most fishes painted on are small goldfishes and small carp fishes, with a diameter around 15 centimeters.

Why Zibo fish plates are mostly of big size is mainly because the big size can meet the need for the practicability of Shandong folk porcelain wares, and is also because it's related to the simple and honest personalities of Shandong people. Shandong people are always generous no matter they put dumplings or dishes into the plates. Zibo fish plates don't belong to porcelains from official kilns, so the plates are not like porcelains from official kilns where the size is strictly controlled, but generally the size of Zibo fish plates is comparatively standard "Fig. 17", "Fig. 18".

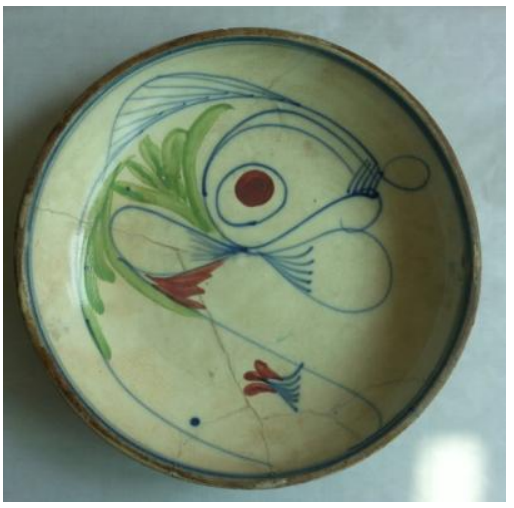

Fig. 17. A (big) fish plate with red and green colors today

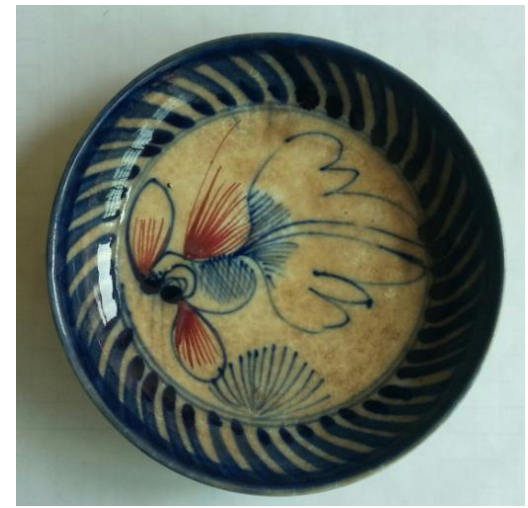

Fig. 18. A blue-and-white (small) fish plate with a red color today.

\section{B. Single Fish Plates and Double Fish Plates}

From the number of fishes in the painting of a Zibo fish plate, the plates can be divided into single fish plates and double fish plates, etc. 
Single fish plates are the most common fish plates in very historical periods, especially the most representative blue-andwhite carp fish plates in the Republic of China. The whole carp fish looks like jumping out of the plate, with its head and tail close to each other, plump and lively, which is deeply favored by people "Fig. 19".

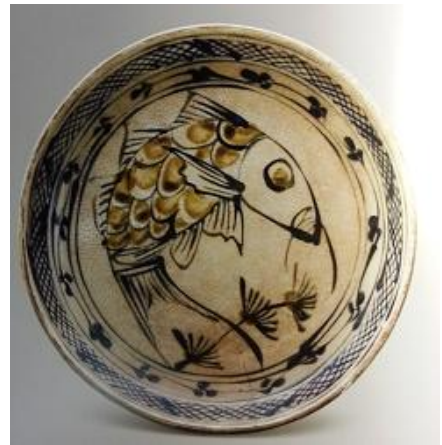

Fig. 19. A blue-and-white porcelain (single)fish plate with a yellow color produced in Qing Dynasty

Chinese people stress that "good things should be in pairs". The two fishes in double fish patterns of Zibo fish plates, either leaning against each other, or twining and combining with each other, as a symbol of combination and reproduction, show the beautiful and happy implied meaning of couples' marriage combination and reproduction with more kids and more happiness "Fig. 20".

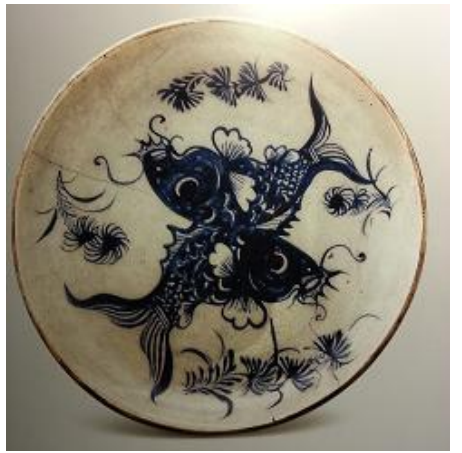

Fig. 20. A blue-and-white porcelain double fish plate produced in the Republic of China

\section{Carp Fish Plates, Goldfish Plates, Fish Plates with a Pattern of fish Transforming into Dragon and Fish Plates} with Transformative Fishes

According to the breeds of the fishes painted on fish plates, they can be divided into carp fish plates, goldfish plates, fish plates with fish transforming into dragon and fish plates with transformative fishes, etc.

Among Zibo fish plates, carp fish plates have the most common fish patterns, and it is related to people's preference for carp fishes. Carp fishes in the folk have a meaning that "there are enough things to spend every year". In the ancient middle region of Shandong, dumplings were mainly placed on big carp fish plates to pray for the whole family to get blessed, joyous and auspicious "Fig. 21".

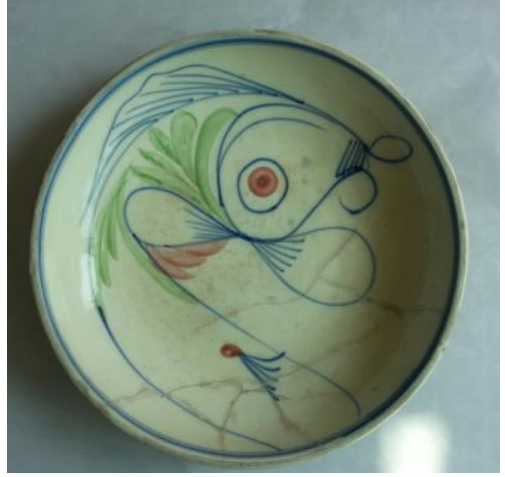

Fig. 21. A blue-and-white porcelain fish plate with a green color produced in the Republic of China

Goldfish plates are mainly painted with goldfishes, implying that "gold and jade fill the hall -- abundant wealth or many children in the family". The goldfish plates are generally painted by blue-and-white with a red color, and the shape of the plates are comparatively standard; the body texture of the plates is light and thin; the decoration uses the comparison of lines' thickness and density, including edging decoration of water eddy patterns and center decoration of swimming goldfishes, and the lines are very delicate and powerful "Fig. 22 .

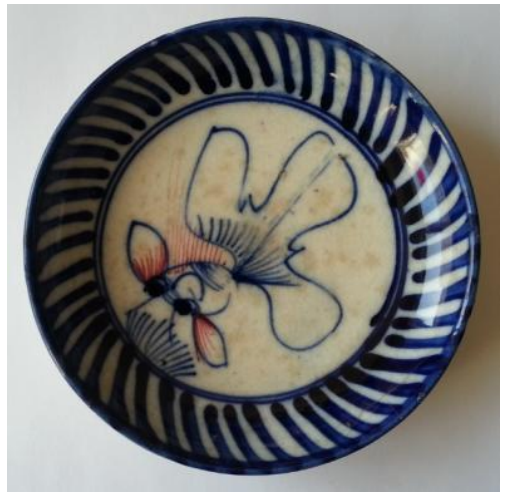

Fig. 22. A blue-and-white porcelain goldfish plate with a little red color produced in the Republic of China

Fish plates with fish transforming into dragon are a very special category of Zibo fish plates. On the back of the fish, wings are painted; dragon's beard is drawn on the fish head; the fish looks like a fish but not fish, and looks like a dragon but not a dragon. This kind of fish pattern looks braver and more open. Fish plates with fish transforming into dragon are good wishes for good achievements on study and future promotion from the folk "Fig. 23". 


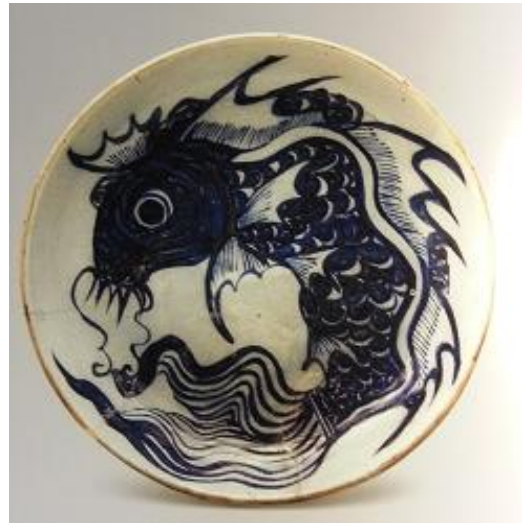

Fig. 23. A white-and-blue fish plate with a pattern of fish transforming into dragon produced in Qing Dynasty

The fish pattems of fish plates with transformative fishes get rid of fish's appearance and form, and are given more profound meanings. For example, the bottom color circle was used to tear the fish apart, which made the original abstract fish pattern look more abstract; writing a Chinese character "Xiang" (which means delicious) expressed people's yearning for delicious food "Fig. 24".

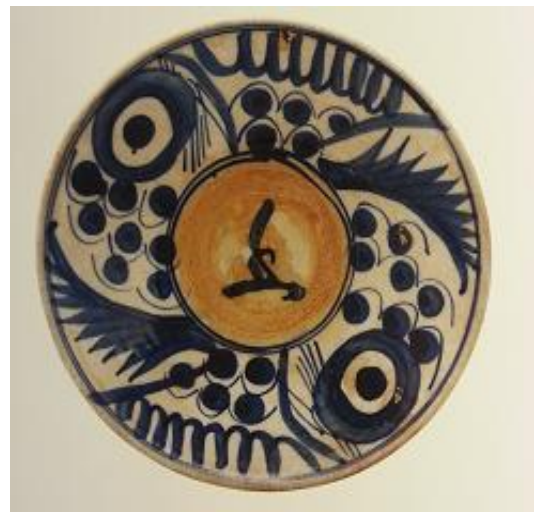

Fig. 24. A blue-and-white porcelain carp fish plate produced in the Republic of China with the pattern of two transformative fishes

\section{Blue-and-White Fish Plates and Fish Plates with Red and Green Colors}

According to glaze colors used in fish plate painting, they can be divided into blue-and-white fish plates, fish plates with black paintings and fish Plates with red and green colors, etc.

Blue-and-white porcelain is the most representative category of Chinese porcelain, belonging to under glazed porcelain. Blue-and-white porcelain takes cobalt ore as its raw material to paint patterns on porcelain the body, and then gets covered with a transparent glaze, and then gets fired into a finished product under a high temperature. Since Ming Dynasty, blue-and-white porcelain fish plates were of the greatest number, and were the representative of Zibo blue-andwhite porcelain wares "Fig. 25".

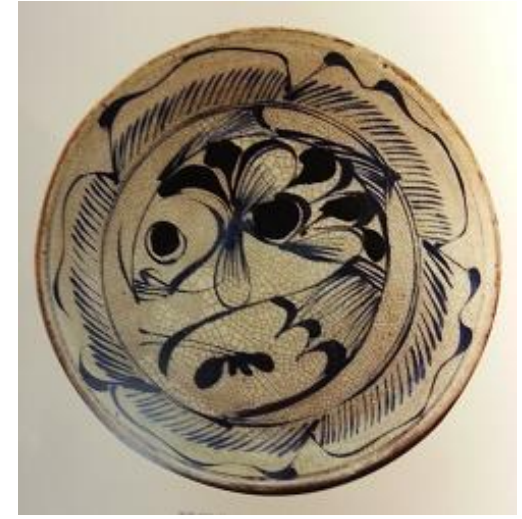

Fig. 25. A blue-and-white porcelain fish plate produced in Qing Dynasty

During the period of the Republic of China, Zibo fish plate with red and green colors developed its own school. This kind of plates took bright red and bright green as main colors. With the improvement of product quality as well as the introduction and development of foreign color materials, "blue with red and green colors" became as the typical national color. Fish plates with red and green colors, colorful and joyous, have good decorating effects "Fig. 26".

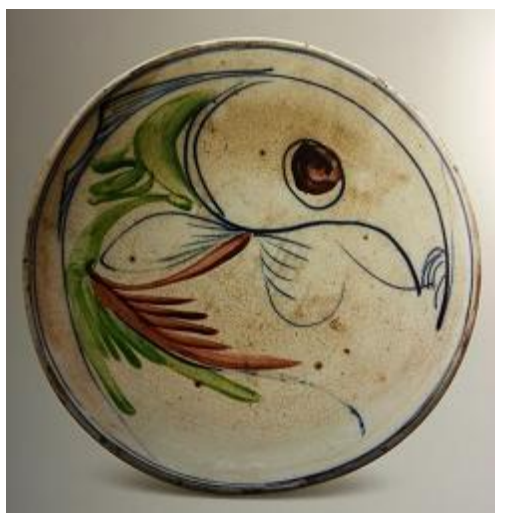

Fig. 26. A white-and-blue porcelain fish plate with red and green colors produced in the Republic of China

\section{E. Fish Plates with Fish Head on the Right and Fish Plates with Fish Head on the Left}

According to the direction where the fish head points to, the fish plates can be divided into fish plates with fish head on the right and fish plates with fish head on the left. Scholar Teng Mingtang estimated that the number of fish plates with fish head on the left only occupied $10 \%$ of the number of fish plates with fish head on the right.

The fish head of fish plates with fish head on the right points to the right side of the plate, showing a swimming state clockwise; on the contrary, the fish head of fish plates with fish head on the left points to the left side of the plate, showing a swimming state anticlockwise. Among fish plates, fish plates with fish head on the right are more common and then number of fish plates with fish head on the left is relatively s mall, which is related to the porcelain painting artists' convenience of using their right hand to paint. A fish plate with fish head on the left and a fish plate with fish head on the right can make a 
couple, and that conforms to the implied meaning of "being in pairs" in Chinese traditional culture, which doubles their artistic value "Fig. 27".

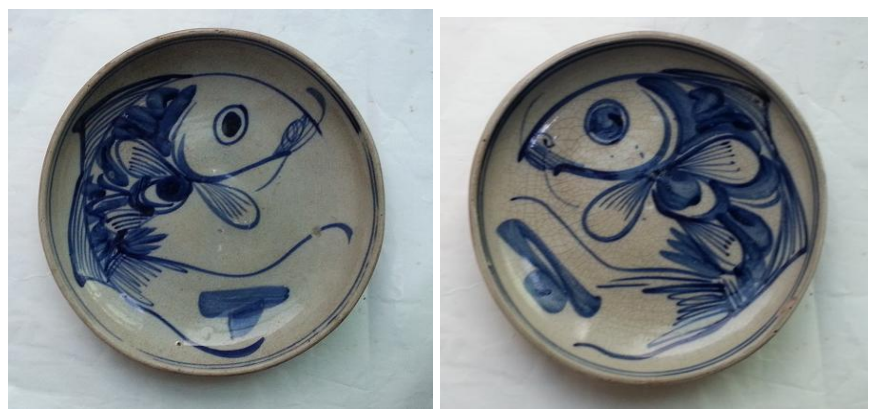

Fig. 27. Two blue-and-white porcelain fish plates produced in the Republic of China

\section{The Cultural Heritage Value Of Zibo Fish Plate}

In recent years, as people's understanding of cultural heritages gets deepen, the value of all kinds of traditional cultures and handicrafts has been deeply excavated. Zibo porcelain firing crafts have been enrolled into the third national intangible cultural heritage list.

Since 1990s, people's cognition and study on Zibo fish plates have improved, and many papers and books talked about Zibo fish plates. However, most of those studying views are the aspects and views from a folk art. In fact, Zibo fish plate is an excellent folk art, and also its traditional producing and painting crafts have a more comprehensive value, which is a cultural heritage worthwhile to be doubly cherished, inherited and developed. Intangible cultural heritages are the quintessence of our national traditional culture as well as the precious wealth of the whole human society, main ly including historical value, cultural value, artistic value, scientific value and social value, etc..

\section{A. The Cultural Value}

Intangible cultural heritages are the human cultural results reflecting people's life, and their cultural value is the core value. Intangible cultural heritages are the effective methods, tools and carriers to convey and reserve cultures, and they can well convey national spirits to every generation and even everyone. Those lively carriers can make a nation with a unique cultural personality and high national spirits.

The cultural connotation of Zibo fish plates is abundant and profound. Zibo fish plate is the excellent representative of Chinese fish culture. Fish, as the earliest cooked food, played its role throughout the whole development process of human society. Chinese fish culture, deep and long, undertakes Chinese nation's great yearning for a beautiful life and their aesthetic purports in different periods. The color-painting fishpatterned pot with a round bottom produced 6000 years ago and unearthed in Qin'an County, Guansu Province, is a fishpatterned pot with the longest diameter found in China, and the pot was painted with a combination of transformative fish patterns and bird patterns. Fishes' strong reproducing ability and their survival mode of living in groups made ancient people have a feeling of respect for fishes, so people placed their wish for race reproduction and wealthy life on the worship of fishes. They repeatedly painted single fish patterns, double fish patterns, three-fish patterns and even the combining patterns of birds and fishes, people and fishes on pottery wares; they hoped the magic power of fishes could convey to human's bodies, which made fish-patterned symbols play a very important role in the worship of totem in the structure of primitive society.

In addition, Zibo fish plates were derived from the folk, and served for people's life; they conformed to the basic principle of practical arts; they took products' functions and effects as basis; they used Zibo local pottery clay and other natural materials as well as traditional porcelain producing techniques; they also closely combined simple and natural folk aesthetics with utility functions; they showed the promoted culture concept in Chinese traditional culture, including the harmony between man and the nature, the unity of man and the nature, and learning from the nature.

\section{B. The Historical Value}

Zibo fish plates have a long history more than 2200 years from the Warring States till now. Zibo fish plates are the typical representative of Zibo folk porcelains, and an important symbol of porcelain walking to popularization, life and secularization. The different producing and painting crafts of Zibo fish plates in different periods are the best reflections of their breaking through ancient laws and innovative development.

Zibo fish plates recorded the developmental history of Zibo porcelains. The production of Zibo porcelains, with a long history, is an excellent representative of Northern folk porcelains. Zibo fish plates and other Zibo porcelain products together composed the glory of Zibo traditional porcelains, and they are the memories of Zibo porcelain history and the historical reflection of Zibo people's diligence and wisdom. Meanwhile, Zibo fish plates reflect the social developmental history of Zibo region in different periods. No matter it is the raw material or the painting technique used by Zibo fish plates, it, to some extent, reflects the historical development in Zibo and even in the middle region of Shandong, including natural resources, cultural ecology, aes thetic orientation as well as folk tradition and fold customs, etc.

\section{The Artistic Value}

Zibo fish plates, originating in the folk, with unique artistic characteristics, are the collective works of folk porcelain producers, and they have an important artistic value:

1. Zibo fish plates are simple and unadorned, with distinctive regional features. Zibo region, located in the north of Yangtze River and close to Yellow River, was influenced by Qi culture and Yellow River culture. Both the producing and the painting of Zibo fish plates are bold and unconstrained, without punctiliousness, which is in accordance with the regional characteristics of Shandong. They are the representatives of northern porcelain arts and also important co 
2. The fish patterns of Zibo fish plates are of various categories, with strong decoration value. Zibo fish plates, according to different classification methods, can be divided into many categories, which has been explained above and will not be explained here again. Moreover, Zibo fish plates, except cylinder fish patterns, also include all kinds of decorative patterns; the variety of categories, the beauty of modeling and the strong decoration value of Zibo fish plate help create its own school among Zibo traditional porcelain art works.

3. The historical development of Zibo fish plates embodied different aesthetic orientations in different periods. From the original realism to the later abstraction, from complicated to simple, and from sole colors to red and green colors together, Zibo fish plates, walking through the road and keeping innovative development, is an excellent representative of folk aesthetics arts.

\section{The Scientific Value}

The production process of Zibo fish plates is complicated, with distinctive regional characteristics. Many originally created techniques played an acceleration role in the progress and development of porcelains, which to some extent reflected the scientific history of porcelain production in Zibo region. For the producing techniques of Zibo fish plates, take the Zibo fish plates in the great prosperity period, from the late Qing Dynasty to the Republic of China, as example. The steps of the producing are respectively the exploitation of raw materials, the choice of materials, the preparation of base clay, the preparation of glaze liquids and engobe mud, molding, fettling, coating engobe mud, coating glazes, color painting, scraping lines and firing, etc.

Zibo fish plates and their producing techniques are the result of collective intelligence created by Zibo local porcelain artists who took advantage of Zibo porcelain firing and painting techniques according to the need of real production life; Zibo potters are the inheritance group of Zibo fish plates and the producing techniques. Zibo potters took local blue clay as raw material and used cattle-driving grinds, with feet in the mud and hands pulling porcelain bases; moreover, they used models to shape wares, painted on their bases by their own hands and finished firing fish plates in steamed bun kilns, to make a living. The potters who painted fish plates are called "craftsmen of fragmental stuffs who played with dog hairs", with a low social position, to make a living and a fortune by painting plates. Every brush stroke showed potters' desires to make a living, the natural revelation of true feelings during potters' hardworking as well as the pursuit and calling of the beauty inside their hearts.

\section{E. The Social Value}

"Yu" (a Chinese character means fish) and "yu" (a Chinese character means something left) have the same pronunciation in Chinese. In the folk, fish means wealth, and also symbolizes reproduction of many kids and the continuation of life. Therefore, in every Spring Festival, even if there are fish plates in a family, the family should buy one or two new fish plates to put dumplings in or cover the special purchased stuffs for the festival, to have good luck, which implies every year have enough things to spend.
The social value and function in new ages need to be expanded. From mere practical wares to multifunctional wares concentrating practicality, ornamental value and collection value, Zibo fish plates should combine traditional producing crafts with cultural experience functions, and allow ordinary people to participate in to improve people's awareness of the culture and make them consciously get involved in the inheritance of the culture.

\section{ZIBO FISH PLATE: INHERITANCE AND INNOVATION IN INSISTENCE AND PROTECTION}

Zibo fish plate, as the typical carrier of Zibo traditional porcelain techniques and the excellent representative of Chinese northern folk porcelains, is an aggregation of cultural heritages, including folk art value, which is worth our double cherishing.

Based on the theoretical perspective of anthropology, for a long time, we paid more attention to the "big tradition" represented by porcelains from official kilns, and a great number of books wrote about it. However, almost no attention was paid to cultural items of the "small tradition" of folk kiln porcelains that were inherited among the folk and represented excellent folk techniques and cultures, and little information and no detailed information were given in all kinds of literatures and documents. Nowadays, although intangible cultural heritages are artificially divided into different levels, such as national level and provincial level, etc., those heritages are all human cultural relics worth double cherishing in essence, and there is no level difference of high and low, and no distinction of good and bad. Under the new historical conditions of the prosperous development of cultural heritage protection and study, we need to review and rethink our cognition of the nation's traditional cultural value, to reconstruct the value on national traditional cultures, especially more humanistic care for the cultural items of the "small tradition".

To be honest, Zibo fish plate gained certain development after new China's establishment, but generally affected by industrialized production and the change of people's life demands, the inheritance and development of Zibo fish plate didn't keep pace with the rapid development of the entire Zibo porcelain industry, and Zibo fish plate was far from the production scale and influence in the Late Qing Dynasty and the Republic of China. With time went by, the industrial production already replaced the production by traditional manual techniques. Monotonous, cheaper and more practical porcelain wares and even plastic wares already occupied most parts of ordinary life demands. Zibo fish plate production and the inheritance of its techniques are facing adverse conditions.

Now, the inheritance and the development of Zibo fish plate porcelain techniques are in an unpromising condition. Batched production of Zibo fish plates is very rare to see. On ly some perseverant porcelain artis ts still stick to this folk cultural heritage by their own smart and industrious hands. The inheritance and innovation of traditional cultures and techniques are the first step to realize cultural selfconsciousness and cultural self-confidence, and also the common mission of cultural scholars and anthropologis ts. Zibo 
fish plates require us to inherit and innovate during our perseverance, and there is still a long way to go.

\section{REFERENCES}

[1] Cao Zaitang. 2009. "Auspiciousness with Fishes: Zitang and Ailing's Fish Plate Study Collection”. [M]. Beijing: China Intercontinental Press. pp. 2.

[2] Wang Bailing, etc. 2009. "Discussion on the Origin and Development of Zibo Fish Plate". [J]. Guanzi Journal. No. 3. pp. 120-121.

[3] Teng Mingtang. 2009. "Discussion on the Art Boutique of Folk Porcelains - Zibo Big Fish P late". [J]. The South of China Today. No. 5. pp. 135.

[4] An Lihua. 2001. "Shandong Big Fish Plate". [M]. Taiei: Taiwan Wuxing Publishing House. pp. 18.

[5] Gu Jun, etc. 2009. "Study on Int angible Cultural Herit age”. [M]. Beijing: Higher Educat ion Press. pp. 36-40.

[6] Ren Mei, etc. 2009. "Chinese Culture of Fish". [M]. Cultural Relics Press. pp. 4-5.

[7] Zhang Zhishou. 2009. "Tang Knows the Happiness of Fishes and Ling Listens to the Sound of Water Waves - Recording Cao Zaitang's Writing His Book Auspiciousness with Fishes: Zitang and Ailing's Fish Plate Study Collection". [M]. Beijing: China Intercontinental Press. pp. 10.

[8] Cao Zaitang. 2009. "Auspiciousness with Fishes: Zitang and Ailing's Fish Plate Study Collection”. [M]. Beijing: China Intercontinental Press. pp. 24. 